\title{
Gynodioecy in the common spindle tree (Euonymus europaeus L.) involves differences in the asymmetry of corolla shapes between sexually differentiated flowers
}

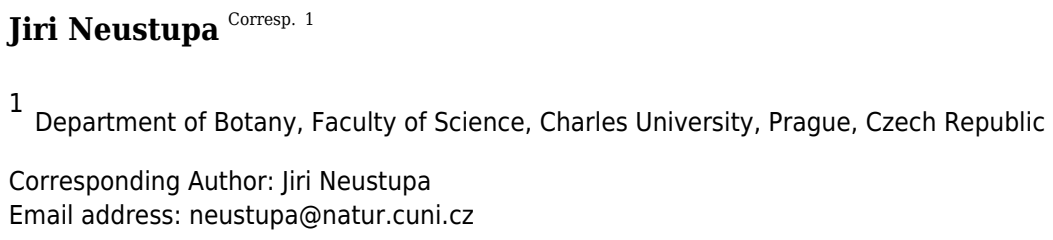

Gynodioecy is typically associated with a smaller perianth size in the purely pistillate flowers than in the hermaphrodite flowers. However, it is unclear whether this size differentiation is associated with any differences in flower shape between the two sexual groups. A geometric morphometric analysis of the symmetry of tetrameric corolla shapes was used in the study of Euonymus europaeus L., Darwin's classical system of floral sexual differentiation. I investigated whether there are any shape differences between the female and bisexual flowers, with respect to both purely symmetric variation involving coordinated shape changes of the four petals and asymmetry among petals within flowers. The corolla shapes of the female and bisexual flowers and the variability among flowers within each sexual group were very similar in the purely symmetric components of shape variation. However, the female flowers were significantly more asymmetric with respect to both the lateral and transversal asymmetry of their corolla shapes. This is the first study to apply geometric morphometrics in the analysis of morphological patterns in a sexually differentiated gynodioecious plant system. The results showed that subtle shape differences in corolla asymmetry differ between the sexual groups and indicate diverging developmental or selection signals between the sexes. 
1 Gynodioecy in the common spindle tree (Euonymus

2 europaeus L.) involves differences in the asymmetry of

3 corolla shapes between sexually differentiated flowers

4

5 Jiri Neustupa ${ }^{1}$

$6{ }^{1}$ Department of Botany, Faculty of Science, Charles University, Prague, Czech Republic

9 Corresponding Author:

10 Jiř́i Neustupa ${ }^{1}$

11 Benatska 2, Prague, 128 01, Czech Republic

12 Email address: neustupa@natur.cuni.cz 


8

\section{Abstract}

Gynodioecy is typically associated with a smaller perianth size in the purely pistillate flowers than in the hermaphrodite flowers. However, it is unclear whether this size differentiation is associated with any differences in flower shape between the two sexual groups. A geometric morphometric analysis of the symmetry of tetrameric corolla shapes was used in the study of Euonymus europaeus L., Darwin's classical system of floral sexual differentiation. I investigated whether there are any shape differences between the female and bisexual flowers, with respect to both purely symmetric variation involving coordinated shape changes of the four petals and asymmetry among petals within flowers. The corolla shapes of the female and bisexual flowers and the variability among flowers within each sexual group were very similar in the purely symmetric components of shape variation. However, the female flowers were significantly more asymmetric with respect to both the lateral and transversal asymmetry of their corolla shapes.

This is the first study to apply geometric morphometrics in the analysis of morphological patterns in a sexually differentiated gynodioecious plant system. The results showed that subtle shape differences in corolla asymmetry differ between the sexual groups and indicate diverging developmental or selection signals between the sexes. 


\section{Introduction}

54 Sexual differentiation of flowers is typically accompanied by morphological differentiation of their components, such as the perianth, in multiple lineages of angiosperms (Barrett \& Hough, 2013; Dufay et al., 2014). Gynodioecy, a dimorphic sexual system where female and

hermaphrodite flowers are borne on different individuals, occurs in approximately $0.6 \%$ of angiosperm species (Delph, 1996; Dufay et al., 2014). The hermaphrodite flowers of gynodioecious species ensure male function during sexual reproduction. They also contain ovules and produce viable seeds, although their number, size, or viability may be significantly lower than that of female individuals (Asikainen \& Mutikainen, 2003; Shykoff et al., 2003; Arnan et al., 2014). The female, purely pistillate flowers may either possess rudimentary staminodes resulting from aborted stamen development or lack any male reproductive structures (Bell, 1985; Delph, 1996). Gynodioecy is widely considered one of the evolutionary pathways from hermaphroditism to complete dioecy (Spigler \& Ashman, 2012; Dufay et al., 2014). However, in many extant species, it is a stable reproductive system with characteristic sexual dimorphism of flowers.

$$
\text { Darwin (1877), in his classical treatise on the sexual differentiation of angiosperms, noted }
$$
that flowers of gynodioecious species typically vary in corolla size, with female flowers being smaller than hermaphrodite flowers. Delph (1996) reviewed sexual dimorphism in gynodioecious and gynomonoecious species from 30 angiosperm families and found that the petals of hermaphrodites were on average approximately 1.3 times larger than those of pistillate flowers. In general, four different but not mutually exclusive explanations have been proposed for this corolla size dimorphism in gynodioecious species (Darwin, 1877; Delph, 1996; Miller \& Venable, 2003; Arnan et al., 2014). The purely mechanistic explanation suggests that 
hermaphrodite flowers tend to be larger because their perianths must enclose a large volume of reproductive parts comprising both ovaries and anthers, whereas the female flowers lack any fully developed male organs (Delph, 1996). A second proposed explanation is that female flower size has decreased as a result of a trade-off allowing them to allocate more resources to fruit and seed production (Miller \& Venable, 2003). However, the decreased size of female corollas may be largely a developmental consequence of stamen abortion (Plack, 1957; Ruan et al., 2005). This explanation, which was already favoured by Darwin (1877), is supported by the developmental connection between the petals and stamens due to the functions of the B-class genes during flower development of dicotyledonous species, in accordance with the $\mathrm{ABCE}$ model (Chanderbali et al., 2016). Finally, it has been argued that the fitness of hermaphroditic individuals, which ensure male function in gynodioecious species, is more affected than that of female individuals by the frequency of pollinator visits, leading to selection for increased corolla size (Müller, 1873; Delph, 1996; Delph \& Ashman, 2006). On the other hand, female fitness may be maximized with relatively fewer visits, imposing weaker selection on their floral display. This idea has led to the conclusion that "flower is primarily a male organ" (Bell, 1985). In support of this explanation, multiple studies have documented the discrimination of pollinators against the smaller female flowers in various gynodioecious taxa (Eckhart, 1991; Delph \& Lively, 1992; Ashman, 2000; Asikainen \& Mutikainen, 2005; Van Etten \& Chang, 2014).

However, the morphological differentiation of the corolla between female and hermaphrodite flowers might involve not only petal size but also shape characteristics. The allometric relation of shape and size is one of the fundamental patterns of morphological variation in the angiosperms (Niklas, 1994). Therefore, it can be expected that consistent differences in corolla size between female and hermaphrodite individuals within populations of gynodioecious species 
99 100

might be accompanied by some kind of shape differentiation (Kamath et al., 2017). However, shape variation of complex structures, such as the corolla of actinomorphic flowers, involves conceptually different and separable components of symmetric and asymmetric variability. Symmetric components are typical by coordinated changes in the shape of all the petals constituting each corolla among different flowers. Thus, this kind of shape variation highlights the differences among flowers, while the petals composing each corolla remain identical. On the other hand, asymmetric variation differentiates the shape of the petals within flowers (Savriama, 2018). Does the sexual differentiation of flowers between female and hermaphroditic individuals involve differences in the symmetric shape components of their corollas? In addition, are there any differences in the patterns and degree of corolla asymmetry between the female flowers that abort their stamens and do not produce any pollen and the hermaphroditic flowers that are solely responsible for the male function within populations? In this study, these questions were investigated by a geometric morphometric analysis of symmetry in corolla shape variation of a well-known gynodioecious species.

Euonymus europaeus L. (the common spindle) is one of Darwin's (1877) classical examples of sexual differentiation in angiosperm flower size. The common spindle belongs to Celastraceae and it is a small tree with a temperate Eurasian distribution area (Popescu et al., 2016). The populations are characterized by a stable gynodioecious reproductive system, with individuals consistently producing either hermaphroditic or purely pistillate flowers with rudimentary staminodes (Darwin, 1877; Webb, 1979; Thomas et al., 2011). Female individuals compose approximately $20 \%$ of a population but generally exhibit higher seed production than hermaphrodites, which possess protandric flowers with functional stamens and pistils (Webb, 1979; Simmons, 2004). The corollas of the female flowers are consistently smaller than those of 
122 hermaphrodite flowers, but no other morphological differences between the sexual forms have 123 been reported in the literature.

Euonymus europaeus is considered a species with truly actinomorphic flowers (Darwin, 1877; Thomas et al., 2011; Idžojtić, 2019). The four petals constituting each corolla as well as the four sepals and stamens or staminodes are considered to be identical, and the flower does not exhibit any consistent differentiation across the left-right or adaxial-abaxial axis (Darwin, 1877; Simmons, 2004; Popescu et al., 2016). From a geometric morphometric perspective of symmetry, the two-dimensional frontal view of the common spindle corolla represents an object with four-fold symmetry arranged according to two perpendicular axes, i.e., a structure with four possible symmetry transformations that in the absence of any asymmetry would leave the object unchanged (Savriama et al., 2010; Savriama \& Klingenberg, 2011; Savriama, 2018; Fig. S1). In this study, geometric morphometric techniques were applied for the first time, to the best of my knowledge, to a sexually separated plant model system. I investigated whether corolla shape of gynodioecious E. europaeus differs between the female and hermaphroditic flowers with respect to both symmetric variation and within-flower asymmetry. The null hypothesis, evaluated through the geometric morphometric analysis of corolla shape, was that the flowers of the females and hermaphrodites differ only in corolla size and that their overall shape features and the asymmetry among the petals constituting each flower are largely identical.

\section{Materials and Methods}


144 The flowers of the common spindle (E. europaeus L.) were sampled within a 2.1 ha area of semi-

145 natural broad-leaved vegetation in Central Bohemia, Czech Republic (50.19583N, 14.03212E),

146 at an altitude of $320-338 \mathrm{~m}$ above sea level. Within this study area the sampled trees were at least

14710 meters from one another. Sampling was performed on May 23-24, 2019, when most

148 individuals at the locality were in peak flowering phase (Fig. 1). In total, 169 flowers from 16

149 individuals ( 8 females, 8 hermaphrodites) were sampled. The sexual identity of each individual

150 was determined by inspecting multiple flowers from different cymes in different stages of flower

151 development. The flowers were photographed at anthesis in planar view and at a fixed distance

152 of $20 \mathrm{~cm}$ using a Canon EOS 1200D (Canon Inc., Oita, Japan) digital camera with an EFS 18-55

153 mm objective. To assess imaging error, each flower was photographed twice independently.

154

155

156

157

158

159

160

161

162

163

164

165

\section{Digitisation of corolla forms}

The corolla forms were digitised using the semi-automatic draw-background-curve function of TpsDig, version 2.22 (Rohlf, 2015). The curves were drawn along the outlines of four petals constituting individual corollas. Then, 50 equidistant points were placed along the outline of each petal (Fig. 2). Thus, the entire configuration, describing the outline form of each analysed corolla, consisted of 200 points (Data S1). To assess digitisation error, all outlines were registered twice, once in a clock-wise direction and once in a counter clock-wise direction. Then, the points from the later digitisation were re-labelled to match the labels of the clockwise digitisation.

\section{Geometric morphometrics}


Geometric morphometric analysis of tetrameric corolla in E. europaeus requires four symmetry transformations prior to actual generalized Procrustes analysis (GPA). These transformations correspond to (1) identity, (2) reflections across horizontal and (3) vertical axes of symmetry (Fig. 2), and (4) reflection across both of these axes (Savriama et al., 2010; Savriama \& Klingenberg, 2011; Klingenberg, 2015; Neustupa, 2017; Savriama, 2018). Note that the symmetry transformations no. 2-4 have to be accompanied by appropriate re-labelling of individual points delimiting the configurations (Klingenberg et al., 2002; Savriama et al., 2010; Klingenberg, 2015; Savriama, 2018). Consequently, the resulting dataset consisted of 169 (original flowers) x 2 (imaging events) x 2 (digitisations) x 4 (symmetry transformations) $=2704$ configurations.

GPA of the configurations involved an additional step that allowed the points along the petal outlines to slide iteratively along the outline tangents so that their final position yielded the smoothest possible deformation of the actual configuration from the mean shape of the entire dataset. This position is characterized by the lowest possible bending energy between the mean shape and each configuration (Bookstein, 1997; Perez et al., 2006; Gunz \& Mitteroecker, 2013). Two marginal points at the base of each petal were treated as fixed landmarks, and 48 points in between were treated as semilandmarks (Fig. 2). The sizes of the configurations were measured as centroid size (CS), the square root of the sum of squared distances of each landmark from their centroid (Zelditch et al., 2012). GPA with sliding semilandmarks was conducted using the function gpagen implemented in the geomorph package, version 3.0.7 (Adams \& OtárolaCastillo, 2013), of R, version 3.5.1 (R Development Core Team, 2018).

\section{Analysis of measurement error and variation among individuals}


189 To analyse the effects of repeated imaging and digitization on shape variation, the configurations

190 resulting from the four symmetry transformations of each object were averaged (Savriama,

191 2018). The shape and size data of these symmetrised configurations were evaluated by two

192 parallel multivariate non-parametric type I Procrustes analysis of variance (ANOVA) models

193 (Klingenberg, 2015). The main fixed effect of "sex" distinguished the flowers taken from the

194 female and hermaphroditic individuals. The effect of "tree", nested within the main fixed factor, 195 evaluated the differences among flowers taken from different individuals. The factor "flower" 196 was nested within "tree" and accounted for the differences among individual flowers within 197 trees. Two factors were used to evaluate measurement error: the imaging error originating from 198 repeat photographs of each analysed flower and the digitisation error arising from imprecision during the registration of the corolla outlines (Berger et al., 2017; Savriama, 2018). Computation of the F-ratios and corresponding p-values for individual effects reflected the nested structure of the data, with p-values based on the random distribution created by permutations of the nearest subordinate nested factors. These analyses were based on 999 permutations. The function procD.Im implemented in the package geomorph, version 3.0.7, was used for this analysis.

Differences in corolla shape between the female and hermaphroditic flowers were also evaluated by multivariate regression of the symmetrised shape data onto the single independent binary factor of sexual group membership. The analysis was implemented in TpsRegr, version 1.42 (Rohlf, 2015), and significance of the model was assessed by 999 permutations on the Goodall's F ratio (Zelditch et al., 2012). Patterns of variation differentiating the sexual morphs were visualized by deformation grids from the overall consensus configuration in TpsRegr.

\section{Analysis of corolla shape symmetry}


212 Principal component analysis (PCA) of shape configurations representing a complete symmetry 213 group yields principal components (PC) corresponding to individual orthogonal subspaces that 214 uniquely describe different types of symmetry and asymmetry among the repeated parts of the 215 analysed structure (Mardia et al., 2000; Savriama et al., 2010; Klingenberg, 2015; Savriama, 2018). In case of the common spindle corolla, the repeated parts are represented by four petals

symmetrically arranged around the reproductive organs. The completely symmetric subspace involves variation among the flowers, wherein the shapes of all four petals are changed in a coordinated fashion and remain mutually identical. This kind of variation corresponds to an ideal actinomorphy or disymmetry of corolla morphology (Culbert \& Forrest, 2016). The positions of four reflected and re-labelled copies of a single corolla on these PCs are exactly identical.

The lateral asymmetry of corolla shape is characterized by shape differentiation between two pairs of adjacent petals within flowers. The flowers of E. europaeus lack any differentiation between the two axes of symmetry dissecting the corolla into two halves, each consisting of two petals (Fig. 2). Thus, PCs describing these lateral asymmetric patterns cannot be distinguished into those highlighting either the left-right or the adaxial-abaxial asymmetry of corolla shapes. Thus, these two subspaces must be combined into a single pattern representing the overall lateral asymmetry. The third group of PCs represents the transversal asymmetry within flowers. The shape variation in this subspace highlights differentiation between two pairs of opposite petals (Savriama, 2018). Two pairs of reflected and re-labelled configurations representing the symmetry group of each analysed corolla on the asymmetric PCs are positioned as mirror images of each other in the opposite parts of the shape space (Savriama \& Klingenberg, 2011).

The amount of each kind of shape asymmetry in individual objects can be evaluated as the sum of their Euclidean distances on PCs representing a particular subspace of asymmetric 
235 variation from the midpoint represented by the ideally symmetric consensus configuration

236 (Neustupa, 2017). Relative amounts of individual subspaces can be quantified by summing the

237 variation spanned by PCs belonging to each of these subsets (Savriama, 2018). It should be noted

238 that the PCA-based approach quantifies the overall amounts of asymmetry in individual

239 subspaces but does not distinguish between directional and fluctuating asymmetry (Savriama et 240 al., 2012).

241 In this study, the GPA-aligned configurations of the complete symmetry groups of female 242 and hermaphrodite flowers were used. The resulting PCs were classified into three subspaces 243 (symmetry, lateral asymmetry, transverse asymmetry). Differences in the variability of female

244 245

246 247

and hermaphrodite flowers in each of these subspaces were quantified by the test for

homogeneity of multivariate dispersions, an analogue of Levene's test for homogeneity of variances (Oksanen et al., 2019). In this analysis, the PC axes describing the individual patterns of symmetry or asymmetry were considered separately, and the multivariate dispersion in the scores of female and hermaphrodite flowers on these axes was compared using the function betadisper of the package vegan, version 2.5-4 (Oksanen et al., 2019) in R, version 3.5.1 (R Development Core Team, 2018). The p-values were based on 9999 random permutations of the original group assignments. In the analysis of symmetric variation, the null hypothesis was that females and hermaphrodites do not differ in the amount of shape variability among flowers. In the analysis of asymmetric subspaces, the null hypothesis was that the amount of within-flower asymmetry in petal shape does not differ between the two sexual morphs.

The multivariate dispersion was visualized by two-dimensional non-metric multidimensional scaling (NMDS) of the PC scores of corolla shape in each of the three analysed subspaces. This ordination technique iteratively reduces the multivariate structure of an original dataset into two 
258 dimensions that approximate their dispersion (Borg \& Groenen, 2005). The resulting two-

259 dimensional plots were very informative for the comparison of the amount of variation between

260 the sexual groups. These NMDS analyses were conducted in PAST, version 2.17c (Hammer et

261 al., 2001).

\section{Results}

The corolla size of the female flowers was approximately $15.5 \%$ smaller than that of the hermaphroditic flowers. This difference was highly significant in the nested ANOVA that evaluated variation in CS of the configurations between two sexual groups against the differed in flower size. The imaging and digitising errors proved to be relatively negligible with regard to size variation among flowers (Table 1). The symmetric corolla shapes of the two sexual morphs were very similar, as their observed difference was not significant compared to the variation between individual trees (Table 2). However, the trees within each group differed in their mean corolla shapes, and the variation among flowers was considerably greater than the error arising from the repeated imaging and digitisation of corolla forms (Table 2).

Multivariate regression of symmetrised corolla shapes against the sexual groups revealed subtle but significant differences (Goodall's $\mathrm{F}=4.21, \mathrm{p}=0.005$ ) that accounted for $2.45 \%$ of the total variation explained by this regression model. In particular, the petals of female flowers had slightly thicker basal parts than those of hermaphroditic flowers (Fig. 3).

The purely symmetric variation, which maintained all four petals within each corolla identical, comprised $45.19 \%$ of total variability in the shape space. In this subspace, all four 
configurations forming the symmetry group of each corolla had the same scores on individual PCs (Fig. 4A). The single most prominent shape pattern within this subspace, illustrated by PC1, described changes in corolla shape resulting from different orientation of flowers that deviated from an actinomorphic shape depicted by the consensus configuration to a disymmetric corolla morphology (Fig. 3). The three subsequent PCs belonging to this subspace, namely, PC4, PC6 and PC7, described shape trends involving coordinated changes in the shape of individual petals. Notably, PC4 illustrated variation between flowers, differentiating those with thick, short and oval petals from those with elongate, thin petals (Fig. 3). PC6 and PC7 exhibited very similar trends corresponding to changes among slightly elongate, obtuse petals and those with pointed, bilaterally asymmetric shapes (Fig. 3).

Together, the two subspaces of lateral asymmetry described $42.88 \%$ of the total variation in corolla shape. The laterally asymmetric axes were delimited in pairs differing by their orientation across two ambiguous axes of symmetry. PC2 and PC3 described changes to corolla shapes with laterally compressed adjacent petals (Fig. 3). Each data point on any of the asymmetric PC axes corresponded to two copies of a particular object. The respective reflection of that object is placed in a mirror position. As the lateral asymmetric axes examined in this study spanned two orthogonal subspaces depicting these asymmetric patterns, the ordination plot of PC2 vs. PC3 shows each object in four symmetrically arranged points corresponding to their mirrored positions on each axis (Fig. 4B). Similarly, PC8 and PC9 illustrated the pattern differentiating between two adjacent short and obtuse petals and the opposite pair exhibiting elongated and pointed shapes (Fig. 3). Transversal asymmetry accounted for $11.93 \%$ of the total variation in corolla shape. The two most important shape trends in this subspace were represented by PC5 and PC10 (Fig. 3). PC5 described within-flower asymmetry characterized by the elongation of 
two opposite petals relative to the other, transversally arranged pair. Similarly, PC10 illustrated asymmetry between the pair of transversally arranged petals with pointed shapes and their counterparts with obtusely widened morphology. The ordination plot of these two PCs belonging to the same asymmetric subspace shows a transversally symmetric arrangement of points, each corresponding to two copies of individual objects mirrored by their corresponding reflections on each axis (Fig. 4C).

The tests of the homogeneity of multivariate dispersions showed contrasting patterns between the subspaces of symmetric and asymmetric variations. In the totally symmetric subspace, there was only a slight difference in the amount of variation between the female and hermaphroditic flowers (Table 3, Fig. 4D). Compared with the hermaphrodite flowers, the female flowers were approximately $9.8 \%$ more variable among each other. However, the confidence intervals for this difference included zero, and the permutation test yielded a p-value for this difference of well above the 0.05 threshold. Thus, the null hypothesis that the dispersion of the female and hermaphrodite symmetric configurations was equal could not be rejected. In contrast, female corolla shapes were considerably more asymmetric than were hermaphrodite corolla shapes in both asymmetric patterns (Table 3, Figs. 4E-F). The multivariate dispersion of female corolla shapes was approximately $23.4 \%$ and $24.2 \%$ higher than that of hermaphrodite corolla shapes in transversal and lateral asymmetry, respectively. In both these subspaces, the difference was highly significant (Table 3). Consequently, the null hypothesis of equal mean within-flower asymmetry of corolla shapes between the two sexual groups was rejected.

\section{Discussion}


327 The attributes of the flowers of the two sexes in the studied population corresponded to Darwin's

328 (1877, p. 288, Fig. 12) original description and subsequent studies (Webb, 1979; Thomas et al.,

329 2011). The data presented in this study confirmed consistent differences in corolla size between

330 the female and hermaphroditic flowers of the common spindle tree, which have been reported in

331 different regions of this plant's distribution (Darwin, 1877; Webb, 1979; Lloyd et al., 1980;

332 Thomas et al., 2011; Popescu et al., 2016). Furthermore, it was also confirmed that E. europaeus

333 in the studied area consistently exhibits gynodioecious reproductive features, with purely

334 pistillate flowers consistently being developed on different individuals than those developing

335 bisexual flowers.

336 Interestingly, the marked size difference between the female and hermaphroditic flowers was 337 not accompanied by any pronounced diversification between morphs in average corolla shape. In 338 fact, the symmetric corolla shapes of females were very similar to those of hermaphrodites, with 339 the sexual group explaining only approximately $2.45 \%$ of the variation in shape in the 340 multivariate regression model. Furthermore, the amount of symmetric shape variability among

flowers was not significantly different between the sexual groups. These results suggest that the species-specific average corolla shapes of E. europaeus are largely consistent regardless of sexual identity of flowers.

However, the analyses of within-flower asymmetry among the four petals constituting the tetrameric corolla of the common spindle revealed significant differences. In both mutually orthogonal subspaces of asymmetric variation, the females consistently had more asymmetric corolla shapes than did the bisexual individuals. Interestingly, the two subspaces of lateral asymmetry represented a considerably greater part of the total variability than the twice the amount of the variation spanned by the subspace of transversal asymmetry. Given the ambiguity 
350 of the two axes of symmetry dissecting the tetrameric flowers of E. europaeus, the components

351 of lateral asymmetry simply describe the shape patterns in which the adjacent petals are more

352 similar than the opposite pair. One possible underlying cause of increased lateral asymmetry may

353 be cryptic and very subtle quantitative zygomorphy of corolla shapes. Such zygomorphy, if

354 present, could not have been detected by the visual inspection of individual flowers, but it may

355 be reflected by increased variation spanned by the components of lateral asymmetry. However, a

356 more plausible explanation of the higher representation of lateral asymmetry involves the effects

357 of environmental heterogeneity around individual flowers. Tucić et al. (2018) recently showed

358 that solar irradiance, which on the northern hemisphere is higher on the southern side of flowers,

359 caused consistent asymmetry of flower parts in Iris pumila. A similar mechanism might operate

360 in the actinomorphic corolla of the common spindle, leading to the increased within-flower

361 asymmetry of petals related to their orientation. Even in an ideally actinomorphic corolla

362 bauplan, this phenomenon can be expected to result in an increased proportion of lateral

363 asymmetry relative to transverse asymmetry. If this explanation holds, it can be predicted that

364 future studies of symmetry in tetrameric corolla shapes in actinomorphic plants in non-tropical

365 latitudes will typically detect a higher proportion of lateral asymmetric variation than of

366 transverse asymmetric variation.

367 However, the higher asymmetry of female flowers in both subspaces is unlikely to be

368 attributable to local environmental heterogeneity. The individual trees in this study were growing 369 in the same habitat and did not differ in overall habit, morphology, or cyme position. In addition, 370 any localised environmental heterogeneity, such as differences in irradiation between different corolla parts, would have hardly influence the components of the transversal asymmetry.

372 However, this subspace was typical by the elevated asymmetry levels of the female flowers, just 
373 like the components of the lateral asymmetry. Therefore, it is unlikely that local environmental

374 effects were responsible for the differences between flowers with differing sexual identities.

375 Thus, it is likely that the observed difference was a result of the gynodioecious reproductive

376 strategy of the studied model system. The developmental explanation of size differences between

377 female and hermaphroditic flowers might be applicable in this case. If the replacement of

378 stamens by staminodes and subsequent lack of pollen production in purely pistillate flowers is

379 associated with the development of petals via the function of the B-class genes (Chanderbali et

380 al., 2016) and thus responsible for their smaller size (Delph et al., 2007), it might also lead to

381 decreased morphological integration of the corolla, resulting in higher shape asymmetry. Similar

382 patterns were recently observed in bisexual Geranium robertianum, where the amount of corolla

383 shape asymmetry was higher in smaller flowers with relatively lower pollen production (Frey \&

384 Bukoski, 2014).

385 Furthermore, the smaller size and greater asymmetry of purely pistillate corollas, related to

386 the changes in the function of the B-class genes, might also lead to the lower visual

387 attractiveness of the female flowers to insect pollinators. Relevant data are not available in $E$.

europaeus, but in other gynodioecious species, such as Fragaria virginiana, Geranium

sylvaticum and G. maculatum, discrimination of pollinators against smaller female flowers has

been reported (Ashman, 2000; Asikainen \& Mutikainen, 2005; Van Etten \& Chang, 2014). In

addition, it has been repeatedly observed that the foraging behaviour of insect pollinators may

reflect intraspecific variability in tetrameric corolla shapes (Gómez et al., 2006; 2008).

Pollinators are known to favour flower models with lower asymmetry, even in the absence of any

rewards, such as increased nectar production (Møller \& Eriksson, 1995; Møller \& Sorci, 1998).

In the case of gynodioecious E. europaeus, this phenomenon would mean that higher selection

Peer) reviewing PDF | (2019:11:43006:1:1:REVIEW 4 Jan 2020) 
396 pressure for frequent visitation by pollinators maintains corolla symmetry at higher levels in 397 hermaphroditic flowers than in female ones.

398 The observed patterns did not support the purely mechanistic explanation of morphological 399 differentiation between the sexual groups (Delph, 1996). If the corollas of female flowers are

400

401

402

403 generally smaller than the corollas of the hermaphrodites solely because the flower volume occupied by the sexual organs is smaller in females, there is no reason to expect any increase in shape asymmetry among the petals of purely pistillate flowers relative to that of the hermaphrodites.

In addition to stable gynodioecy, transitional patterns of sexual differentiation have been reported in other taxa with actinomorphic corolla morphology. It might be interesting to study these systems using similar analytical procedures of geometric morphometric decomposition of shape symmetry (Klingenberg, 2015; Savriama, 2018; Tucić et al., 2018). For example, a transition from fully bisexual to purely pistillate flowers within a gradient of individuals differing in the number of active stamens has been identified in populations of Geranium sylvaticum, which typically exhibits a pentameric corolla morphology (Asikainen \& Mutikainen, 2003; 2005). In addition, several co-existing sexual types, including purely unisexual, inconstant unisexual, ambisexual and bisexual individuals, have been reported in Thymelaea hirsuta, a species with tetrameric actinomorphic flowers (Shaltout \& El-Keblawy, 1992; Dommée et al., 1995). In these systems, the possible effects of stamen abortion on within-flower corolla asymmetry could be tested in complex settings, which might confirm or disprove the generality of this phenomenon and its developmental explanation.

\section{Conclusions}


This pioneering study illustrated that geometric morphometric analyses of corolla shape

421

422

423

424

425

426

427

428

429

430

431

432

433

434

435

436

437

438

439

440

441

symmetry in taxa with sexual differentiation may yield interesting and novel insights into

phenotype evolution of unisexual and combined reproductive systems in angiosperms. It has

been showed that morphological differentiation of flowers in gynodioecious E. europaeus is not

limited to size diminution of female flowers but also involves significant differences between sexual types in corolla shape variation. Whereas the symmetric corolla shapes were very similar between the purely pistillate and bisexual flowers, considerable differences in within-flower asymmetry were detected between the sexual forms. The corolla shapes of females were consistently more asymmetric in the subspaces of both lateral and transversal asymmetry. These patterns of a less integrated corolla in purely pistillate flowers suggest the effects of developmental processes related to stamen abortion, which decrease the ontogenetic precision in petal development, potentially acting together with the preference of insect pollinators for symmetric corolla shapes.

The gynodioecy pathway to the fully separated monoecious sexual reproduction of angiosperms represents a unique microevolutionary stage in which flower morphology may gradually diverge due to diverging selection pressures related to the frequency of pollinator visits (Ashman, 2000; Van Etten \& Chang, 2014) and to developmental interactions among flower parts (Thompson et al., 2002; Ruan et al., 2005). Geometric morphometrics of flower shape symmetry now offers brand new possibilities for the study of these microevolutionary processes.

\section{Acknowledgements}

The author thanks Wiley Editing Services for English language editing and style corrections. 
443

444

445 446

447

448

449

450

451

452

453

454

455

456

457

458

459

460

461

462

\section{References}

Adams DC, Otárola-Castillo E. 2013. geomorph: an R package for the collection and analysis of geometric morphometric shape data. Methods in Ecology and Evolution 4:393-399 DOI: $\underline{10.1111 / 2041-210 X .12035 .}$

Arnan X, Escolà A, Rodrigo A, Bosch J. 2014. Female reproductive success in gynodioecious Thymus vulgaris: pollen versus nutrient limitation and pollinator foraging behaviour. Botanical Journal of the Linnean Society 175:395-408 DOI: doi.org/10.1111/boj.12173.

Ashman TL. 2000. Pollinator selectivity and its implications for the evolution of dioecy and sexual dimorphism. Ecology 81:2577-2591 DOI: doi.org/10.1890/00129658(2000)081[2577:psaiif]2.0.co;2.

Asikainen E, Mutikainen P. 2003. Female frequency and relative fitness of females and hermaphrodites in gynodioecious Geranium sylvaticum (Geraniaceae). American Journal of Botany 90:226-234 DOI: doi.org/10.3732/ajb.90.2.226.

Asikainen E, Mutikainen P. 2005. Preferences of pollinators and herbivores in gynodioecious Geranium sylvaticum. Annals of Botany 95:879-886 DOI: doi.org/10.1093/aob/mci094.

Barrett SCH, Hough J. 2013. Sexual dimorphism in flowering plants. Journal of Experimental Botany 64:67-82 DOI: doi.org/10.1093/jxb/ers308.

Bell G. 1985. On the function of flowers. Proceedings of the Royal Society London B 224:223265 DOI: doi.org/10.1098/rspb.1985.0031. 
463 464 465 466 467 468 469

Berger BA, Ricigliano VA, Savriama Y, Lim A, Thompson V, Howarth DG. 2017. Geometric morphometrics reveals shifts in flower shape symmetry and size following gene knockdown of CYCLOIDEA and ANTHOCYANIDIN SYNTHASE. BMC Plant Biology 17:205 DOI: doi.org/10.1186/s12870-017-1152-x.

Bookstein FL. 1997. Landmark methods for forms without landmarks: morphometrics of group differences in outline shape. Medical Image Analysis 1:225-243 DOI: doi.org/10.1016/s1361-8415(97)85012-8.

Borg I, Groenen P. 2005. Modern multidimensional scaling: theory and applications. New York: Springer.

Chanderbali AS, Berger BA, Howarth DG, Soltis PS, Soltis DE. 2016. Evolving ideas on the origin and evolution of flowers: new perspectives in the genomic era. Genetics 202:12551265 DOI: doi.org/10.1534/genetics.115.182964.

Culbert BM, Forrest JRK. 2016. Floral symmetry affects bumblebee approach consistency in artificial flowers. Journal of Pollination Ecology 18:1-6 DOI: doi.org/10.26786/1920$\underline{7603(2016) 10 .}$

Darwin C. 1877. The different forms of flowers on plants of the same species. New York: D. Appleton \& Company.

Delph LF. 1996. Flower size dimorphism in plants with unisexual flowers. In: Lloyd DG, Barrett SCH, eds. Floral Biology. New York: Chapman \& Hall, 217-240.

Delph LF, Ashman TL. 2006. Trait selection in flowering plants: how does sexual selection contribute? Integrative and Comparative Biology 46:465-472 DOI: doi.org/10.1093/icb/icj038. 
485

486

Delph LF, Touzet P, Bailey MF. 2007. Merging theory and mechanism in studies of gynodioecy. Trends in Ecology and Evolution 22:17-24 DOI: doi.org/10.1016/j.tree.2006.09.013.

Delph LF, Lively CM. 1992. Pollinator visitation, floral display, and nectar production of the

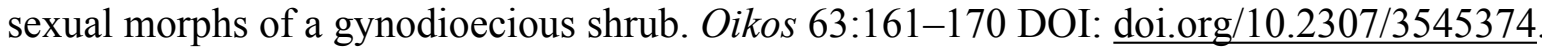

Dommée B, Biascamano A, Denelle N, Bompar JL, Thompson JD. 1995. Sexual tetramorphism in Thymelaea hirsuta (Thymelaeaceae): morph ratios in open-pollinated progeny. American Journal of Botany 82:734-740 DOI: doi.org/10.2307/2445612.

Dufay M, Champelovier P, Käfer J, Henry JP, Mousset S, Marais GAB. 2014. An angiospermwide analysis of the gynodioecy-dioecy pathway. Annals of Botany 114:539-548 DOI: doi.org/10.1093/aob/mcu134.

Eckhart VM. 1991. The effects of floral display on pollinator visitation vary among populations of Phacelia linearis (Hydrophyllaceae). Evolutionary Ecology 5:370-384 DOI:

doi.org/10.1007/bf02214154.

Frey FM, Bukoski M. 2014. Floral symmetry is associated with flower size and pollen production but not insect visitation rates in Geranium robertianum (Geraniaceae). Plant Species Biology 29:272-280 DOI: doi.org/10.1111/1442-1984.12021.

Gómez JM, Perfectti F, Camacho JPM. 2006. Natural selection on Erysimum mediohispanicum flower shape: insights into the evolution of zygomorphy. The American Naturalist 168:531545 DOI: $\underline{\text { doi.org/10.1086/507048. }}$

Gómez JM, Bosch J, Perfectti F, Fernández JD, Abdelaziz M, Camacho JPM. 2008. Spatial variation in selection on corolla shape in a generalist plant is promoted by the preference 
506

507

patterns of its local pollinators. Proceedings of The Royal Society B 275:2241-2249 DOI: doi.org/10.1098/rspb.2008.0512.

Gunz P, Mitteroecker P. 2013. Semilandmarks: a method for quantifying curves and surfaces. Hystrix - Italian Journal of Mammaliology 24:103-109 DOI: doi.org/10.4404/hystrix-24.1$\underline{6292 .}$.

Hammer Ø, Harper DAT, Ryan PD. 2001. PAST: Paleontological statistics software package for education and data analysis. Palaeontologia Electronica 4:1-9.

Idžojtić M. 2019. Dendrology. Cones, flowers, fruits and seeds. London: Academic Press.

Kamath A, Levin LA, Miller JS. 2017. Floral size and shape evolution following the transition to gender dimorphism. American Journal of Botany 104:451-460 DOI: doi.org/10.3732/ajb.1600442.

Klingenberg CP. 2015. Analyzing fluctuating asymmetry with geometric morphometrics: concepts, methods, and applications. Symmetry 7:843-934 DOI: $10.3390 /$ sym7020843.

Klingenberg CP, Barluenga M, Meyer A. 2002. Shape analysis of symmetric structures: quantifying variation among individuals and asymmetry. Evolution 56:1909-1920 DOI: 10.1111/j.0014-3820.2002.tb00117.x.

Lloyd DG, Webb CJ, Primack RB, 1980. Sexual strategies in plants II. Data on the temporal regulation of maternal investment. New Phytologist 86:81-92 DOI: doi.org/10.1111/j.14698137.1980.tb00781.x.

Mardia KV, Bookstein FL, Moreton IJ. 2000. Statistical assessment of bilateral symmetry of shapes. Biometrika 87:285-300 DOI: doi.org/10.1093/biomet/87.2.285. 
527 Miller JS, Venable DL. 2003. Floral morphometrics and the evolution of sexual dimorphism in

528 Lycium (Solanaceae). Evolution 57:74-86 DOI: doi.org/10.1111/j.0014-

$529 \quad$ 3820.2003.tb00217.x.

530

531

532

533

534

535

536

Møller AP, Eriksson M. 1995. Pollinator preference for symmetrical flowers and sexual selection in plants. Oikos 73:15-22 DOI: doi.org/10.2307/3545720.

Møller AP, Sorci G. 1998. Insect preference for symmetrical artificial flowers. Oecologia 114:37-42 DOI: doi.org/10.1007/s004420050417.

Müller H. 1873. Die Befruchtung der Blumen durch Insekten und die gegenseitigen Anpassungen beider. Leipzig: Wilhelm Engelmann Verlag.

Neustupa J. 2017. Asymmetry and integration of cellular morphology in Micrasterias compereana. BMC Evolutionary Biology 17:1 DOI: 10.1186/s12862-016-0855-1.

Niklas KJ. 1994. Plant allometry: the scaling of form and process. Chicago: The University of Chicago Press.

Oksanen J, Blanchet FG, Friendly M, Kindt R, Legendre P, McGlinn D, Minchin PR, O'Hara RB, Simpson GL, Solymos P, Stevens MHH, Szoecs E, Wagner H. 2019. vegan: Community Ecology Package. R package version 2.5-4. Available at https://CRAN.Rproject.org/package=vegan (accessed 8 November 2019).

Perez SI, Bernal V, Gonzales PN. 2006. Differences between sliding semi-landmark methods in geometric morphometrics, with an application to human craniofacial and dental variation. Journal of Anatomy 208:769-784 DOI: doi.org/10.1111/j.1469-7580.2006.00576.x.

Plack A. 1957. Sexual dimorphism in Labiatae. Nature 180:1218-1219 DOI: doi.org/10.1038/1801218a0. 
549 Popescu I, Caudullo G, De Rigo D. 2016. Euonymus europaeus in Europe: distribution, habitat, 550 usage and threats. In: San-Miguel-Ayanz J, De Rigo D, Caudullo G, Houston Durrant T, 551 Mauri A, eds. European Atlas of Forest Tree Species. Luxembourg: Publications Office of 552 the EU, 92-93.

553

554

555

556 557

558

559

560

561 562

R Development Core Team 2018. R: A language and environment for statistical computing. Available at https://cran.r-project.org/bin/windows/base/old/3.2.3/(accessed 8 November 2019).

Rohlf FJ. 2015. The tps series of software. Hystrix Italian Journal of Mammalogy 26:9-12 DOI: $\underline{10.4404 / \text { hystrix-26.1-11264. }}$

Ruan CJ, Qin P, Han RM. 2005. Floral morphology and stigma-anther separation in gynomonoecious-gynodioecious Kosteletzkya virginica (Malvaceae). South African Journal of Botany 71:367-373 DOI: doi.org/10.1016/s0254-6299(15)30111-3.

Savriama Y. 2018. A step-by-step guide for geometric morphometrics of floral symmetry. Frontiers in Plant Science 9:1433 DOI: doi.org/10.3389/fpls.2018.01433.

Savriama Y, Gómez JM, Perfectti F, Klingenberg CP. 2012. Geometric morphometrics of corolla shape: dissecting components of symmetric and asymmetric variation in Erysimum mediohispanicum (Brassicaceae). New Phytologist 196:945-954 DOI: doi.org/10.1111/j.1469-8137.2012.04312.x.

Savriama Y, Klingenberg CP. 2011. Beyond bilateral symmetry: geometric morphometric methods for any type of symmetry. BMC Evolutionary Biology 11:280 DOI: 10.1186/14712148-11-280. 
570 Savriama Y, Neustupa J, Klingenberg CP. 2010. Geometric morphometrics of symmetry and allometry in Micrasterias rotata (Zygnematophyceae, Viridiplantae). Nova Hedwigia Beihefte 136:43-54.

Shaltout KH, El-Keblawy AA. 1992. Sex expression in Egyptian Thymelaea hirsuta (Thymelaeaceae) populations. Plant Systematics and Evolution 181:133-141 DOI: doi.org/10.1007/bf00937440.

Shykoff JA, Kolokotronis SO, Collin CL, López-Villavicencio M. 2003. Effects of male sterility on reproductive traits in gynodioecious plants: a meta-analysis. Oecologia 135:1-9 DOI: doi.org/10.1007/s00442-002-1133-Z.

Simmons MP. 2004. Celastraceae. In: Kubitzki K, ed. The families and genera of vascular plants VI. Berlin: Springer Verlag, 29-64.

Spigler RB, Ashman TL. 2012. Gynodioecy to dioecy: are we there yet? Annals of Botany 109:531-543 DOI: doi.org/10.1093/aob/mcr170.

Thomas PA, El-Barghathi M, Polwart A. 2011. Biological flora of the British Isles: Euonymus europaeus L. Journal of Ecology 99:345-365 DOI: doi.org/10.1111/j.1365$\underline{2745.2010 .01760 . x}$.

Thompson JD, Rolland AG, Prugnolle F. 2002. Genetic variation for sexual dimorphism in flower size within and between populations of gynodioecious Thymus vulgaris. Journal of Evolutionary Biology 15:362-372 DOI: doi.org/10.1046/j.1420-9101.2002.00407.x.

Tucić B, Budečević S, Manitašević Jovanović S, Vuleta A, Klingenberg CP. 2018. Phenotypic plasticity in response to environmental heterogeneity contributes to fluctuating asymmetry in 
591 plants: first empirical evidence. Journal of Evolutionary Biology 31:197-210 DOI:

$592 \quad$ doi.org/10.1111/jeb.13207.

593 Van Etten ML, Chang SM. 2014. Frequency-dependent pollinator discrimination acts against

594 female plants in the gynodioecious Geranium maculatum. Annals of Botany 114:1769-1778

595 DOI: $\underline{\text { doi.org/10.1093/aob/mcu204. }}$

596 Webb CJ. 1979. Breeding system and seed set in Euonymus europaeus (Celastraceae). Plant

597 Systematics and Evolution 132:299-303 DOI: doi.org/10.1007/bf00982391.

598 Zelditch ML, Swiderski DL, Sheets DH. 2012. Geometric morphometrics for biologists: $a$ 599 primer. London: Elsevier Academic Press.

600 


\section{Figure 1}

Flowers of Euonymus europaeus.

(A-D) Female flowers with a central pistil and four pollen-less staminodes. (E-H) Bisexual flowers bearing both the central pistil and four stamens. Scale bar (included in A) $=3 \mathrm{~mm}$.

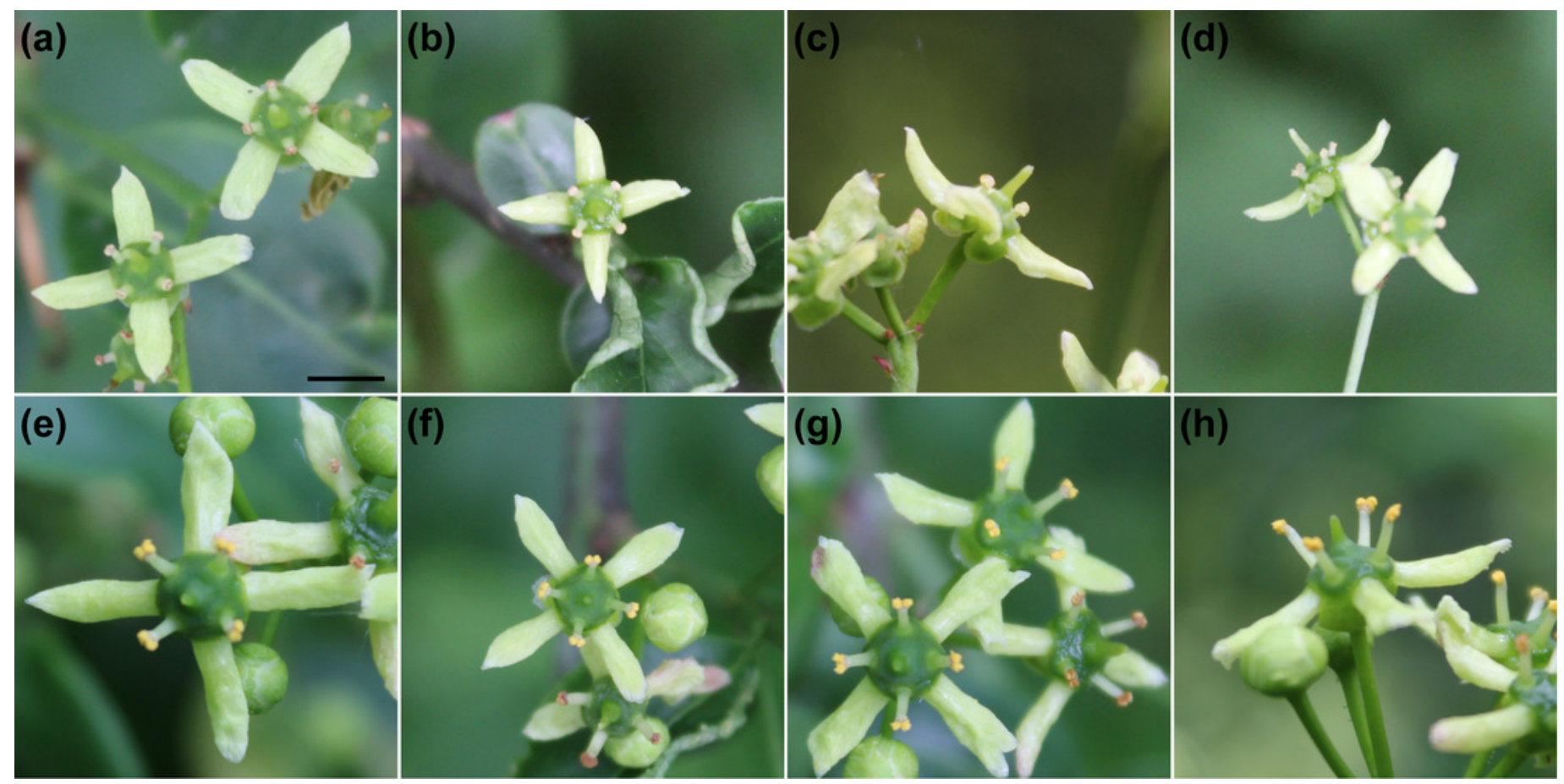


Figure 2

A flower of Euonymus europaeus with 50 equidistant semilandmarks placed along the outline of each petal.

Two axes of symmetry dissecting the tetrameric corolla are indicated by the blue lines. 


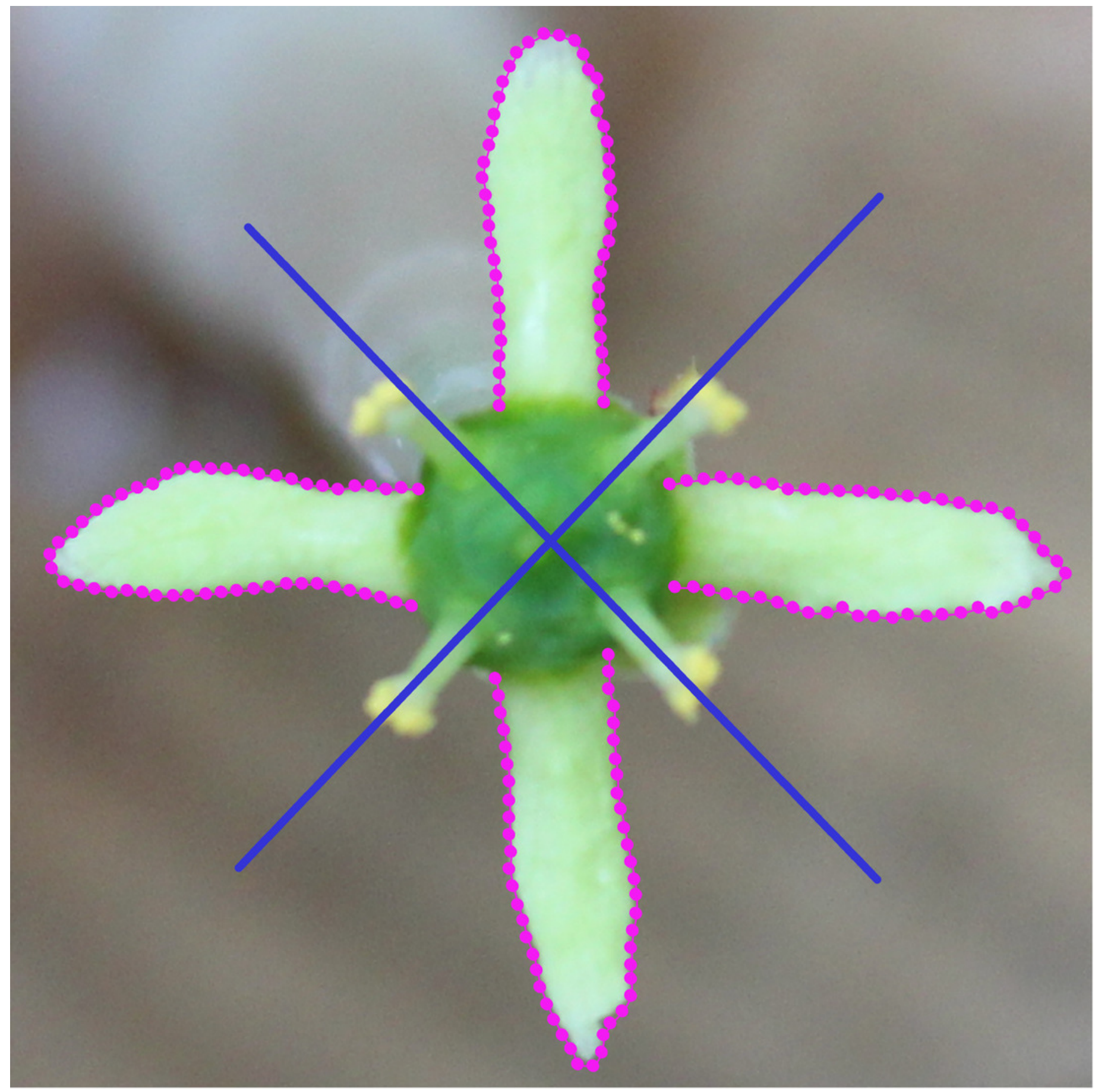




\section{Figure 3}

A scheme showing the configurations of Euonymus europaeus corolla reconstructed by the principal component analysis of biradial symmetry and by the linear discriminant analysis of two sexual morphs.

(A-T) The first ten principal components are shown. The configurations illustrate shapes typical for the most marginal occupied positions within the shape space. Blue configurations indicate the components depicting the purely symmetric variation. Violet indicates the components spanning two subspaces of lateral asymmetry. Green depicts the components showing the patterns of transversal asymmetry in corolla shapes. (U) The histograms showing relative amounts of variation spanned by symmetry and two types of within-flower asymmetry. (V) Configuration of the consensus corolla shape and the typical features differentiating $(\mathrm{W})$ the female and $(\mathrm{X})$ hermaphroditic flowers in the linear discriminant analysis. The differences between the sexual morphs are four times enhanced for better visibility. 

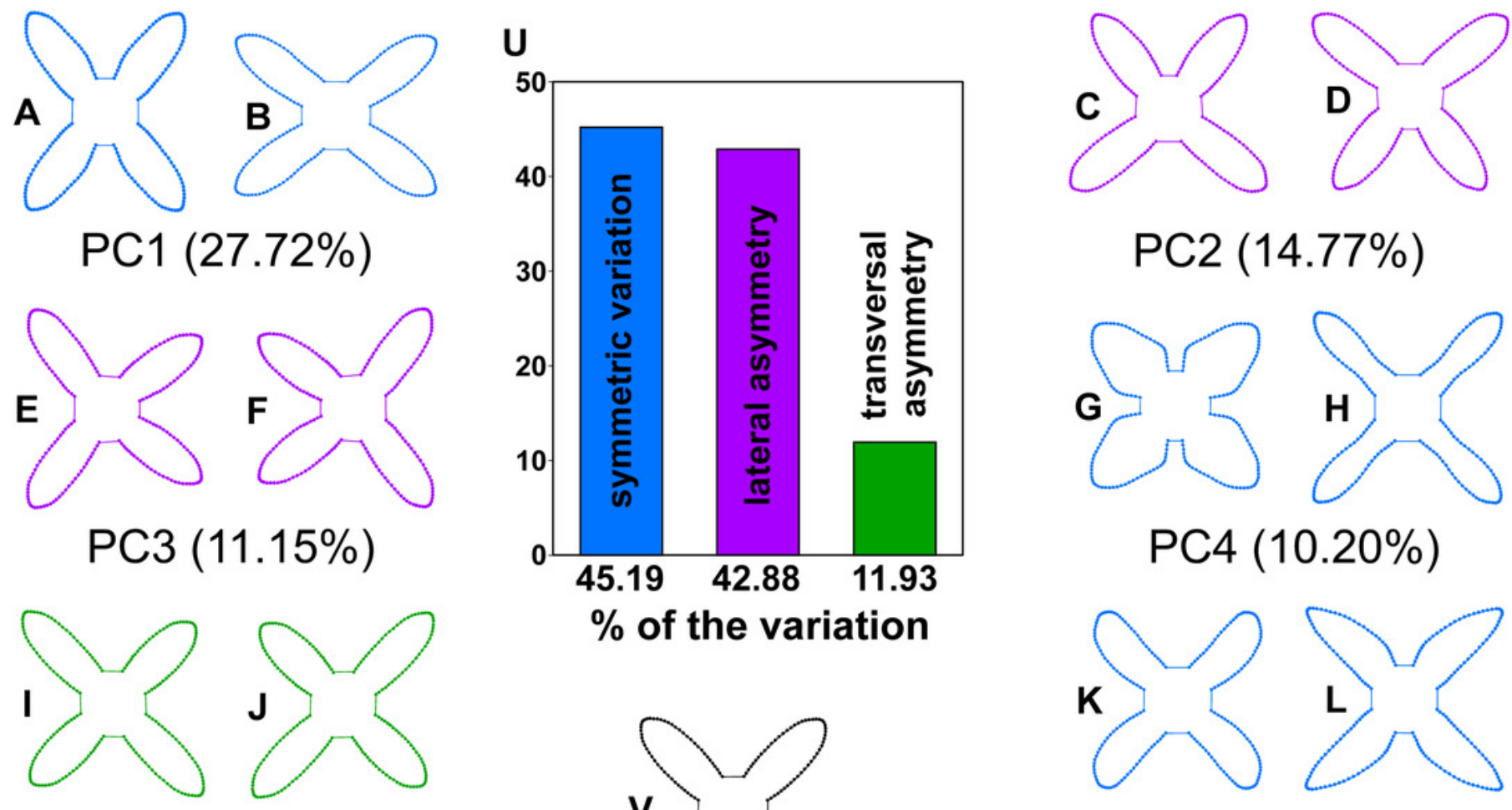

PC5 (4.62\%)

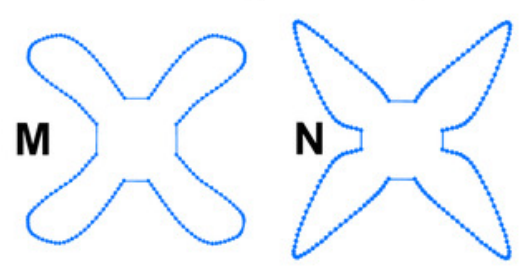

PC7 (3.34\%)
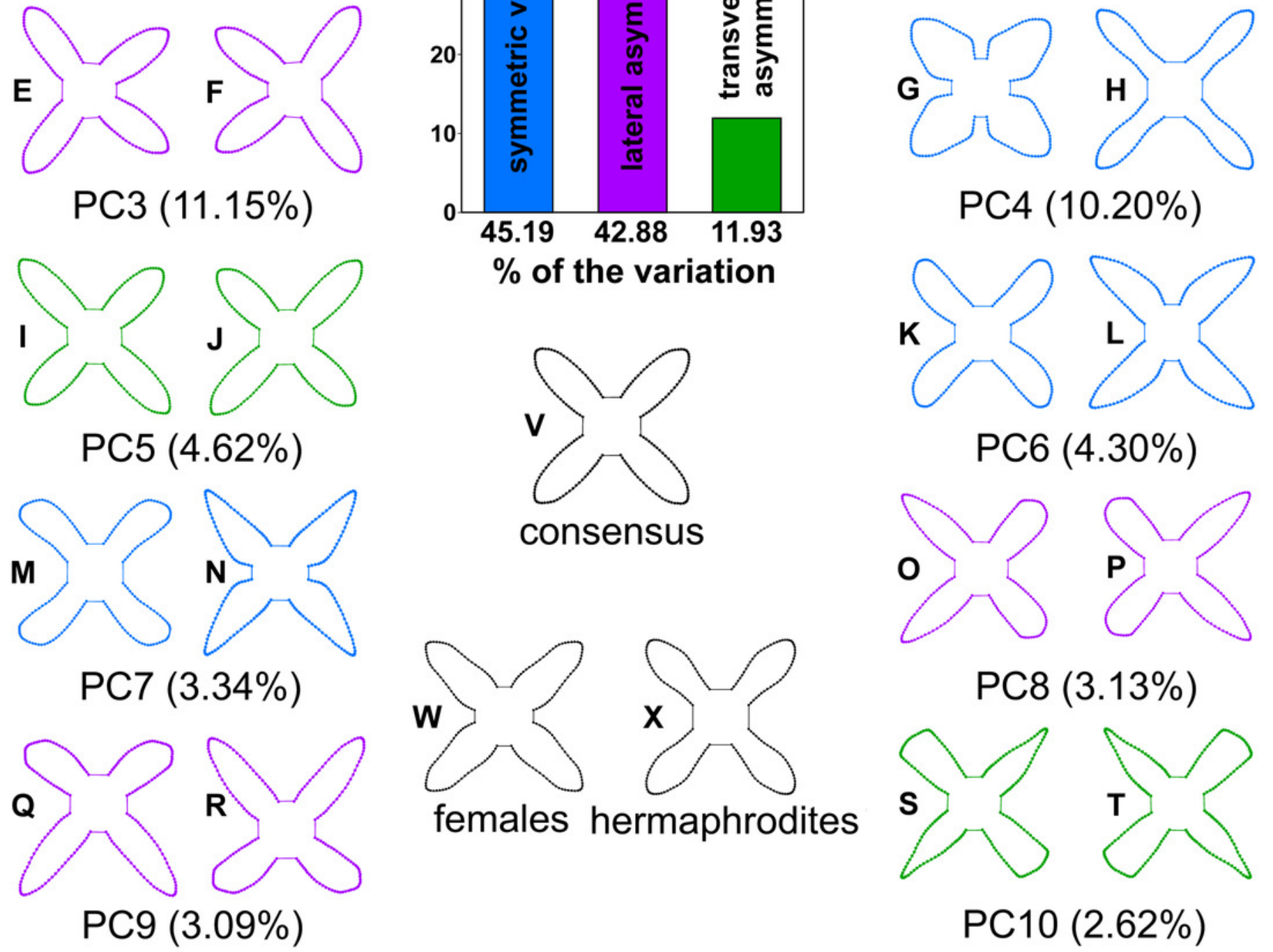

PC10 (2.62\%) 


\section{Figure 4}

Plots showing the ordination structure and the amounts of variability in corolla shapes of sexually differentiated flowers of Euonymus europaeus.

Positions of the purely pistillate flowers (magenta) and hermaphroditic flowers (green) are depicted. (A) Two principal components (PCs) describing the symmetric variation show a pattern with each data point representing four symmetry transformations of a single corolla.

(B) PCs describing two mutually orthogonal patterns of lateral asymmetry. Each corolla is represented by four data points occupying mirror positions on each axis. (C) PCs representing the laterally asymmetric subspace of the variation. Four symmetry transformations of each corolla occupy two data points in mirror positions in the shape space. (D) Two-dimensional non-metric multidimensional scaling (NMDS) plot showing the overall amounts of symmetric variation in female (red) and hermaphroditic (green) flowers. Kruskal's stress $=0.22$. (E) NMDS plot showing the overall amounts of variation in PCs spanning the subspaces of lateral asymmetry in both sexual groups. Kruskal's stress $=0.24$. (F) NMDS plot showing the overall amounts of variation in PCs spanning the transversal asymmetry of corolla shapes in both sexual groups. Kruskal's stress $=0.26$. The $95 \%$ variation ellipses for each sexual group are depicted in the NMDS plots. 

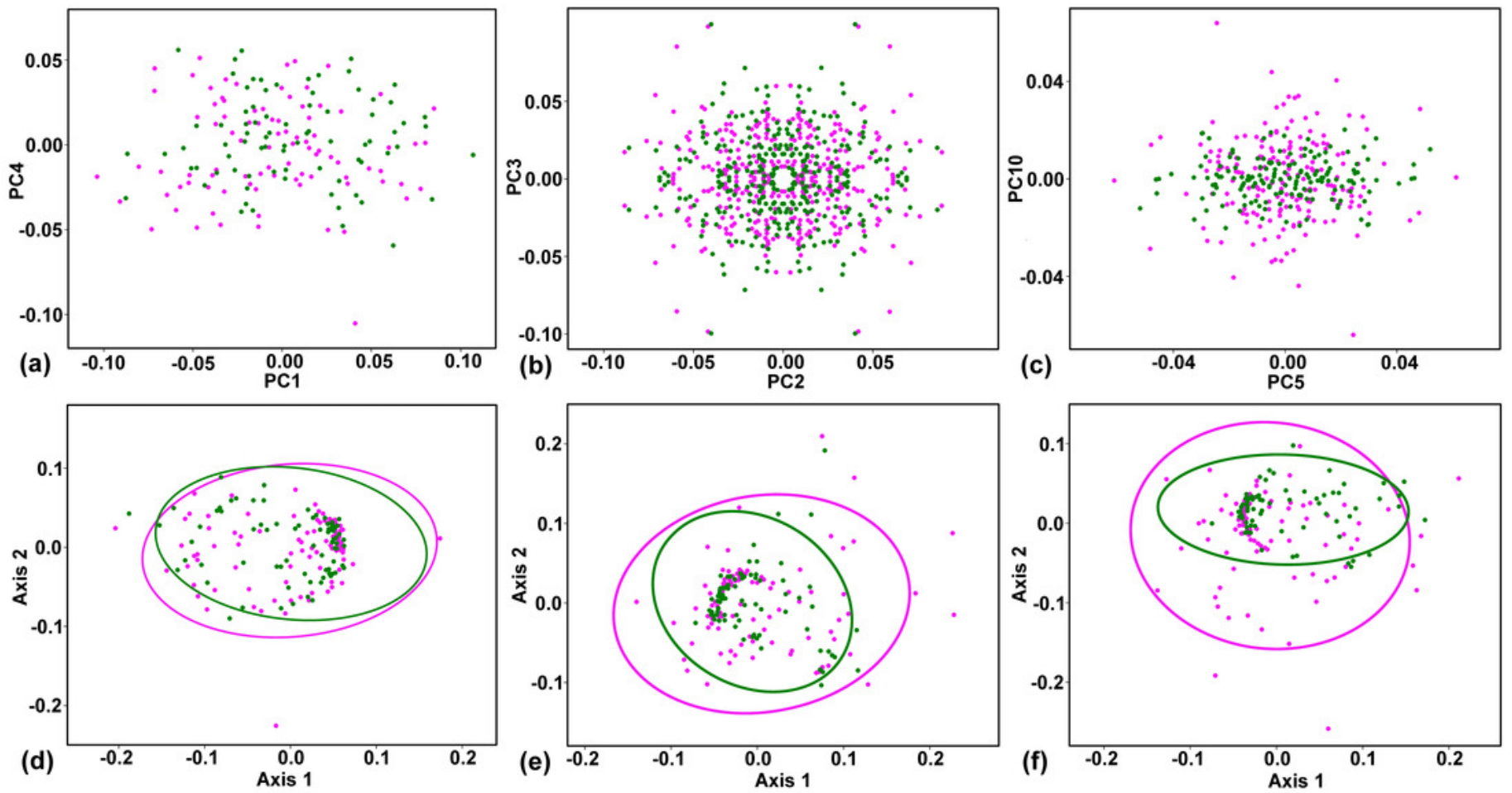


\section{Table $\mathbf{1}$ (on next page)}

Results of analysis of variance evaluating variation in centroid size of the corolla in female and hermaphroditic flowers of Euonymus europaeus. 
1

\begin{tabular}{lcccccc}
\hline Source & Df & SS & MS & $\boldsymbol{\eta}^{\mathbf{2}}$ & $\mathbf{F}$ & p-value \\
\hline Sex & 1 & $7.01 \times 10^{7}$ & $7.01 \times 10^{7}$ & 0.635 & 36.999 & 0.002 \\
Tree (sex) & 14 & $2.65 \times 10^{7}$ & $1.89 \times 10^{6}$ & 0.240 & 21.578 & 0.001 \\
Flower (tree) & 153 & $1.34 \times 10^{7}$ & $8.78 \times 10^{4}$ & 0.122 & 39.032 & 0.001 \\
Imaging error & 169 & $3.80 \times 10^{5}$ & $2.25 \times 10^{3}$ & 0.003 & 19.107 & 0.001 \\
Digitising error & 338 & $3.98 \times 10^{4}$ & $1.18 \times 10^{2}$ & 0.0004 & & \\
Total & 675 & $1.10 \times 10^{8}$ & & & & \\
\hline
\end{tabular}

2 Df, degrees of freedom; SS, sum of squares; MS, mean squares; $\eta^{2}$, percentage of variance 3 explained by individual effects 


\section{Table 2 (on next page)}

Results of Procrustes analysis of variance of symmetric corolla shape variation in female and hermaphroditic flowers of Euonymus europaeus. 
1

\begin{tabular}{lcccccc}
\hline Source & Df & SS & MS & $\boldsymbol{\eta}^{\mathbf{2}}$ & $\mathbf{F}$ & p-value \\
\hline Sex & 1 & 0.054 & 0.054 & 0.024 & 1.384 & 0.225 \\
Tree (sex) & 14 & 0.542 & 0.039 & 0.243 & 3.699 & 0.001 \\
Flower (tree) & 153 & 1.602 & 0.010 & 0.717 & 103.683 & 0.001 \\
Imaging error & 169 & 0.017 & 0.0001 & 0.008 & 1.858 & 0.001 \\
Digitising error & 338 & 0.018 & 0.00005 & 0.008 & & \\
Total & 675 & 2.234 & & & & \\
\hline
\end{tabular}

2 Df, degrees of freedom; SS, sum of squares; MS, mean squares; $\eta^{2}$, percentage of variance 3 explained by individual effects 


\section{Table 3(on next page)}

Results of tests for homogeneity of multivariate dispersions.

The tests evaluated the amounts of corolla shape variation in different subspaces of morphometric symmetry and asymmetry between the purely pistillate and hermaphroditic flowers of Euonymus europaeus. 
1

\begin{tabular}{lcccccc}
\hline & \multicolumn{2}{c}{$\begin{array}{c}\text { Average ED to } \\
\text { centroid }\end{array}$} & $\begin{array}{c}\text { Diff. in } \\
\text { means }\end{array}$ & \multicolumn{2}{c}{$\begin{array}{c}95 \% \text { C.I. } \\
\text { of diff. in means }\end{array}$} & P-value \\
\cline { 2 - 7 } & FM & HM & & LR & UR & \\
\hline $\begin{array}{l}\text { Symmetric variation } \\
\text { among flowers }\end{array}$ & 0.0561 & 0.0511 & 0.0050 & -0.0016 & 0.0116 & 0.1323 \\
\hline $\begin{array}{l}\text { Lateral asymmetry } \\
\text { within flowers }\end{array}$ & 0.0580 & 0.0467 & 0.0113 & 0.0053 & 0.0173 & 0.0010 \\
\hline $\begin{array}{l}\text { Transversal asymmetry } \\
\text { within flowers }\end{array}$ & 0.0301 & 0.0244 & 0.0058 & 0.0024 & 0.0091 & 0.0006 \\
\hline
\end{tabular}

2 C.I., confidence interval; FM, females; HR, hermaphrodites; LR, lower range; UR, upper range 3 